\title{
LA COMUNICABILIDAD SIMBÓLICA EN PALABRA FUGITIVA (1964) DE YOLANDA WESTPHALEN
}

\section{THE SYMBOLIC COMMUNICABILITY IN YOLANDA WESTPHALEN'S PALABRA FUGITIVA (1964)}

\author{
Frich Enrique Flores Sobenes \\ Universidad Nacional Mayor de San Marcos \\ frich.flores@unmsm.edu.pe \\ https://orcid.org/0000-0002-8625-9552 \\ DOI: $10.36286 / \mathrm{mrlad} . v 3 i 5.61$
}

Fecha de recepción: 21.11.19 | Fecha de aceptación: 10.05.20

\begin{abstract}
RESUMEN
La obra de Yolanda Westphalen aporta una voz propia al contexto al cual perteneció, un marco realmente agitado por la cantidad de escritores prolíficos que surgieron durante todo el periodo. En Palabra Fugitiva (1964), su estilo domina la forma expresiva moldeada por la figura del símbolo y regula el halo hermético, característico de este. A partir del eje temático de la reflexión amorosa y la realidad, su poesía configura una voz que plasma una estética del lenguaje. Mediante la retórica comparada, cotejamos uno de los poemas de la poeta Julia Ferrer con el de Westphalen para ofrecer una reflexión final con el fin de confirmar nuestra propuesta de lectura.
\end{abstract}

PALABRAS CLAVE: poesía, símbolo, comunicación, comparación, Palabra Fugitiva.

\begin{abstract}
Yolanda Westphalen's literary work provides a self-voice to the context where it belonged, a frame of reference shaken by all the prolific writers. In Palabra Fugitiva (1964), her style dominates the way of communicating molded by the symbol and regulates the hermetic halo, which is the principal characteristic of this figure. Thus, from the thematic axis on loving reflectión and reality, her poetry configures a voice that captures an aesthetic of
\end{abstract}


language. Through comparative rhetoric, we compare one of the poems by the poet Julia Ferrer with that of Westphalen to offer a final reflection in order to confirm our reading proposal.

KEYWORDS: poetry, symbol, communication, comparison, Palabra Fugitiva.

\section{INTRODUCCIÓN}

La producción de la obra de Westphalen posee una característica transitiva debido a que aparece entre dos generaciones. Una noticia publicada en la página web de la Universidad Nacional Mayor de San Marcos (2018) menciona lo siguiente: "Yolanda [...] fue colaboradora de periódicos y revistas culturales. Si bien cronológicamente pertenece a la denominada generación del 50, empezó a publicar recién en la década del 60” (párr. 8).

Ambos períodos reúnen a una gran cantidad de escritores que marcaron el camino que llevaría la literatura peruana. Debido a la rapidez de figuras destacadas que surgieron en ambos periodos dejaremos de lado la partición e intentaremos abordar este amplio panorama como uno solo, basándonos en los autores canónicos de aquella época. Ricardo Sumalavia (2003) habla de un ciclo que condensó "personalidades de renombre, en el campo de la narrativa, como Carlos Eduardo Zavaleta, Julio Ramón Ribeyro, Enrique Congrains, Vargas Vicuña y tantos otros, hasta Luis Loayza y Mario Vargas Llosa”. (p. 1)

El período previo, los 50, concertó las bases para la gestación de la vanguardia en los años 60. La vanguardia literaria, por el lado de la narrativa, introdujo técnicas literarias provenientes de la literatura europea y la popularización del cine como el monólogo interior, el cambio de perspectiva, el dinamismo de los saltos temporales y espaciales, etc. Este fenómeno atrajo la atención de la crítica, debido a que uno de sus integrantes, Mario Vargas Llosa, empezó a recibir reconocimiento tras la publicación de su primer libro Los jefes en 1959. 
El género de la poesía resulta algo complejo, debido al desarrollo expresivo, variado y personal de cada uno de sus representantes. Esta etapa concentró poetas como Javier Sologuren, Washington Delgado, Jorge Eduardo Eielson, Blanca Varela, Sebastián Salazar Bondy, Carlos Germán Beli, entre otros. De manera similar a los narradores, los poetas muestran en sus retóricas elementos asimilados de las vanguardias europeas. Un ejemplo de esto sucede con el surrealismo. Antonio Cisneros (1992) analiza la adaptación de este movimiento en las poéticas de escritores como Romualdo, Lauer y Sologuren. El autor menciona que los dos primeros son lejanos a las ideas que primaban la liberación onírica a excepción del último de quien "es evidente el privilegio del subconsciente, lo irracional. No habla, claro está, de escritura automática, aunque privilegia ese flujo sobre el que no tenemos control".

La obra de Yolanda Westphalen ha sido explorada aún con poca profundidad. Por ejemplo uno de los aspectos que destaca la crítica es un rol de género:

Perteneciente a la llamada Generación del 50, Yolanda Westphalen es cabal representante de uno de los más importantes propósitos de esta generación: liberar la palabra femenina. Baste recordar en ese empeño a mujeres de la talla de Blanca Varela, Cecilia Bustamante o Lola Thorne (De la Vega, 2007, p. 36).

Creemos que es una interpretación válida si se la compara con autoras de su generación. No obstante, como acotamos en el resumen, este poemario pretende centrarse en una exploración sobre el lenguaje. A las lecturas sobre su obra se añade una propuesta que la lee a partir de un prisma filosófico:

La obra poética de Yolanda Westphalen, una de las más importantes de la Generación del 50 en el Perú y prominente voz de la lírica hispanoamericana, se caracteriza por una acendrada vocación filosófica y lo canónico de sus versos que traducen con sabiduría cotidiana aquel delirio interior que la sume constante en la bruma metafísica (Troiano, 2008, párr. 1).

Westphalen, a diferencia de sus coetáneos, elige un camino propio en su poesía: la senda del simbolismo. Palabra fugitiva propone una reflexión sobre el arte verbal como hecho del lenguaje, motivo que comparte con la antagónica vanguardia. Su exploración 
redefine la utilización del símbolo y logra manifestar un complejo discurso centrado en el trabajo estético que explora la conexión entre la palabra y el mundo.

Con el propósito de analizar a profundidad su poemario Palabra fugitiva, analizaremos el poema "XV". Utilizaremos la categoría de campo figurativo de Arduini (2000) quien propone que la relación entre hombre y figura es mucho más compleja para solo reducirla al campo estético. A partir del análisis de las figuras procederemos a configurar al interlocutor, así mismo, veremos cuál es la dinámica de la argumentación utilizando dos tipos de técnicas argumentativas de Perelman y Olbrechts-Tyteca (1989): la apariencia-realidad y el enlace con lo simbólico para de esta manera determinar la forma en que el hablante sortea la diferencia entre realidad y ensoñación a partir del pensamiento simbólico. Seguidamente, determinaremos la visión del mundo, una categoría de Giovanni Bottiroli, para internarnos en la visión de la voz poética y determinar que existe una dicotomía entre lo real y el mundo de la psique que configuran un discurso simbólico sobre la palabra, manifestada estéticamente a través del individuo.

Finalmente, con el fin de ofrecer una mirada distinta sobre el tratamiento del símbolo, nuestro análisis concluirá con una comparación retórica del poema " $\mathrm{XV}$ " con el poema nombrado "Poema" de Julia Ferrer, publicado en la revista La casa de cartón en el año de 1981. La comparación la realizaremos bajo el sustento del autor Tomás Albaladejo (2008) quien prioriza el mecanismo comparativo cuando se propone ampliar el campo de resultados y conocimientos sobre la materia que se estudia.

\section{LOS RASTROS DEL SIMBOLISMO EN PALABRA FUGITIVA: UNA REDUCCIÓN DEL CAMPO RETÓRICO}

Es necesario aproximarnos a la idea del símbolo según nuestra propuesta. Jaques Rancière intenta conceptualizar esta figura a partir de uno de los escritores más emblemáticos de este movimiento: Stéphane Mallarmé. De acuerdo con el autor, el símbolo se define, o aproximadamente se entiende, como el querer sugerir a través de imágenes y metáforas del poema, a los que llama "material" sugerente: 
[...] el poema mallarmeano explota un lote finito de imágenes y metáforas del poema, donde más de una se pierde en la noche de los tiempos: riesgo y soledad de la obra arrojada a la fortuna de la olas, coros celestes y cisnes con alas cautivas [...] En gran medida, el material es antiguo y también las maneras en que sirve de símbolo. Queda por saber qué quiere decir «material» y en que consiste exactamente el acto de simbolizar. Hemos definido una traducción de las hipótesis iniciales del poema. ¿Pero qué hemos hecho exactamente con eso? ¿Dice lo que el poema «quiere decir»? Pero es en la idea misma del «querer decir» donde se juega la singularidad de la empresa que asoció el nombre genérico del «símbolo»al nombre propio de Mallarmé (2015, p. 23).

El simbolismo, tal como lo explicita Rancière, es una especie de estampa que no pretende comunicar, sino sugerir algo, lo que asimilado por un lector se transforma en interpretación. Ahora es importante establecer una demostración de la utilización de dicho concepto en el poemario. Una primera comparación se puede establecer a partir del título: Palabra fugitiva. El adjetivo "fugitiva" permite reflexionar sobre la factibilidad de la comunicación. A manera de lectura simbólica, el poemario propone que la división bipartita de la palabra, entendida como signo lingüístico, adquiere un significado variable.

El aparato metafórico que bien podríamos adecuar dentro del simbolismo es muy grande y en ocasiones complejo. Por ejemplo ilustremos con el poema "XIV": "Árboles de aceite / flores de musgo / gaviota hecha de viento" (Westphalen, 2018, p. 60) La comunicación con este tipo de metáforas se complejiza puesto que se estaría asociando dos tipos de paisajes: el marino, relacionado a la gaviota; y el boscoso, asociado al árbol y al musgo. Las comparaciones realizadas sugieren antítesis al igual que el contraste entre los dos paisajes. Además de ello, se confronta el contenido semántico de los propios símbolos: la dureza de un árbol con la fluidez del aceite, la belleza de una flor con la uniformidad del musgo o la tangibilidad del animal con la intangibilidad del viento. Se interpreta entonces que los símbolos son capaces de construir una nueva realidad comunicable a través de la voz poética.

El poema "XXI" permite corroborar la afirmación y añadir un aspecto particular de la procedencia del símbolo: "Dorada la tarde viene / a hilvanar sus palabras" (Westphalen, 2018, p. 65) En este caso la tarde se hace acreedora del adjetivo “dorada", el cual realza su 
valor como algo preciado si lo leemos como una metáfora que la equipara al color del oro. Valioso, porque la personificación con la que se simboliza a la tarde destaca su importancia en cuanto a una imagen inspiradora para la voz poética, quien invisibiliza su presencia y deja el control de la actividad creadora a la tarde. Por tanto, se hace plausible a partir de esta lectura que la construcción de un nuevo mundo tiene una procedencia: la naturaleza. Y que esta nueva edificación a partir del símbolo pretende justificarse utilizando la palabra misma. Es decir, que esta hace posible la sugerencia de una nueva realidad.

Nos aproximamos entonces a una lectura, a partir de interpretaciones de versos, en la que el concepto simbolista se muestra a través de un "querer decir". Sin embargo, el tratamiento, a diferencia del símbolo mallarmeano que busca el hermetismo total, en este poemario se presenta de una manera ligeramente diferente, puesto que sí busca hacerse comunicable. Las nuevas realidades pretenden justificar una reflexión sobre el contenido semántico de la palabra capaz de realizar una modificación estética de la realidad. Una realidad asociada a motivos naturales donde se destaca la belleza de dichos objetos mediante el ejercicio de la poesía y al mismo tiempo posibilitan una reflexión sobre esta. En eso recae una de las particularidades de la utilización del matiz simbólico y revela la asimilación y la sutilidad personal para la expresión del símbolo de Yolanda Westphalen. Ampliaremos esta interpretación en los apartados siguientes.

\section{LA BÚSQUEDA DE LA PALABRA EN REPRESENTACIONES CON FORMA DE SILUETAS: ANÁLISIS}

Iniciaremos una descripción del poemario empezando por su título: Palabra fugitiva. Este plantea un primer rastro semántico por el que iniciar una aproximación. Creemos que el título traza una reflexión sobre la palabra en el quehacer poético, un acto que destaca la creatividad a través del ejercicio simbólico. Nuestra argumentación para probar ello inicia con el enfoque sobre los títulos de los poemas, puesto que de los 28 poemas solo tres fueron titulados. Analizaremos brevemente los poemas que poseen título, porque cuando estos son materializados por el hablante los contenidos se difuminan figurativamente. 
Consideramos dicho acto como la persecución por la nominación de los objetos, una búsqueda que sugiere la redefinición de la realidad a partir del lenguaje.

Junto al título individual de cada poema, se crea a través de las metáforas una red de significados que acentúan la búsqueda del quehacer poético. En los contenidos sucede algo similar que repercute en las temáticas de los poemas. Por ejemplo, en el primer poema titulado "Marina" se retrata un paisaje marino mediante el uso de metáforas que definen un personaje que cumplirá el rol del amado: "tu cuerpo es una larga figura geométrica [...] Redes gigantes se despedazan sobre la playa" (Westphalen, 2018, p. 55) En estos versos destaca el intento por hacer colisionar en significación a sustantivos que comparten el hilo semántico marino: las redes, el cuerpo, la playa. Esto retrata la búsqueda incesante de figuras para representar la descripción de un escenario.

Otro de los poemas que acompaña esta tesis es "Réquiem". Consideramos que la elección de este término no ha sido en vano, puesto que su significado alude a la composición musical en una misa de difuntos. La ausencia de la palabra es lo que predomina en este poema. De esta manera se representan siluetas, como si el contenido semántico estuviera desaparecido: "Mariposas de sombra tiemblan en flores ausentes" (Westphalen, 2018, p. 57) La muerte está presente, pero no es el tema principal porque la voz está desemantizando la materia: solo hay sombras y ausencia de objetos. La persona amada se representa disociada de su cuerpo y permanece solo la persona gramatical junto a su muerte: "Solo tu cuerpo avanza hacia una agonía de estrellas inconclusas / solo tú y tu muerte" (Westphalen, 2018, p. 57) El espacio temporal es en extremo complejo, porque generalmente entendemos la muerte como el final de la vida, pero en este espacio la muerte existe al mismo tiempo que el tú. Sucede algo similar en los versos anteriores, notamos la carencia de contenido a partir de personificaciones cuyas corporalidades están ausentes.

El siguiente y último poema, titulado sugestivamente "Nada", es el final de la categoría de poemas que poseen título. Nuevamente se desprenden redes semánticas que pretenden desvincularse de lo que forma su significación a partir de una focalización en la persona amada: "transparentes jardines tu mirada [...] Aquí la noche sin destino y sin 
sombras / Aquí la noche clara como un río, vacía de luna [...]” (Westphalen, 2018, p. 61) La noche contrariamente a lo que es, pierde la mayor parte de su significado si se ilumina con la figura del río. El silencio final del poema se equipara a la búsqueda de la palabra para expresar el contenido poético de sí misma. Además, esta búsqueda parece distinguir el contenido como algo propio y separado del mundo, en una forma de pensamiento lingüístico en el que el signo se separa del objeto que representa y representa una realidad a través de las sombras y la transparencia.

Estos poemas sirven para entender la tesis principal del poemario: la palabra que huye a la representación del contenido y la lucha del hablante por redefinir, mediante la poesía, la realidad. Con motivo de centrarnos en el análisis completo de un poema en específico para mostrar la relación entre la voz poética y la realidad seleccionamos el poema "XV":

\section{XV}

Niebla.

Fantasía absurda de viento y agua.

Se enciende el frío en la ceniza de la tarde.

Avanza cautelosa la ciudad.

De lo profundo del silencio emerge tu sonrisa vive, sueña, viaja, solo el rumor de la nostalgia perdura como una lámpara hueca.

Flores de sombra violentan tu recuerdo.

Los dos contemplamos el paisaje como una imagen muerta reflejada en un espejo que un vacío mortal lo ha liberado de su horizonte de cristal.

Y ahora solo perdura lo fugitivo de la niebla.

(Westphalen, 2018, pp. 60-61). 


\subsection{SEGMENTACIÓN}

Dividiremos el poema en cuatro partes: narración, introducción, argumentación y peroración o epílogo. La narración dibuja un paisaje nostálgico y lleno de figuras antitéticas resonantes en la temática nostálgica del poema. Este segmento narrativo abarca desde el primer al cuarto verso. El segundo segmento del poema lo denominamos introducción y abarca del quinto al séptimo verso. Este segmento presenta una tesis, la cual muestra a un amado que trae dicha al enunciador del poema. La aparición del amante permite concluir que el poema desarrolla una temática amorosa-nostálgica. El siguiente segmento, el de la argumentación, va desde el octavo al decimoquinto verso. En este el amado se desintegra en el recuerdo y el paisaje presentado se tiñe de mortandad, tal como enuncian los versos decimoprimero y segundo. La peroración final se puede establecer en los últimos versos, decimosexto y decimosétimo, los cuales reafirman la pérdida del amado en el mundo real al compararlo con los recuerdos de una niebla fugitiva.

Una explicitación mayor de la tesis se puede establecer de la siguiente manera: el amado trae dicha al amante y embellece el paisaje que el amado ensombrece. A partir de este poema establecemos la relación que existe entre amor, mundo y recuerdos. Para enlazar la sugerencia simbólica y su significación analizaremos el siguiente nivel.

\subsection{CAMPOS FIGURATIVOS}

Antes de analizar los campos figurativos del poema primero es necesario establecer qué se entiende por aquel concepto. En un principio, el autor Stefano Arduini define a la figura literaria para luego dar cuenta de dicho concepto. La figura según el autor se entiende como la palabra inicial y nace como una especie de relación entre hombre y mundo, es decir, aparece como una forma creativa de relacionar la expresión y las cosas. De esta manera, cuando la expresión se hace presente también lo hacen los campos figurales, que son espacios que asocian las diferentes características de las figuras literarias:

La palabra puede perder en la conciencia de los hablantes la certeza de ser en su origen figura, pero permanece en ella que la figura es el aspecto creativo e innovador del 
lenguaje: sin figuras no tendríamos lenguaje estándar, y no al contrario [...] Demos paso ahora al análisis de los campos figurativos dentro de los cuales incluiremos todo el universo figurativo (Arduini, 2000, p. 103).

Definidos los campos figurales como un espacio donde surgen relaciones entre objetos y figuras, enfocaremos la utilización de estas en los poemas.

En el poema "XV" predomina fuertemente el campo figurativo de la metáfora, que abarca principalmente la metáfora, símbolo y símil. También hay una breve incidencia del campo figurativo de la antítesis, cuya figura principal es la antítesis, por eso nos centraremos en primar esta.

El primer campo se conforma por la figura del símbolo, que sugiere motivos melancólicos mediante los términos de la niebla y la tarde. La utilización de la metáfora conforma un segundo campo, más amplio y generalmente de la forma estructural, es decir forma un concepto o denominación en términos de otro, como por ejemplo ceniza de la tarde, donde la tarde a manera de fogata produce cenizas, o profundo silencio, donde el silencio es una especie de contenedor cuyo final es la profundidad.

La siguiente metáfora utilizada es la ontológica. Esta utiliza las experiencias del hablante en términos de objetos. Por ejemplo, en el verso décimo se utilizan las flores como si fueran bellos recuerdos, por otro lado, la figura "sombras" sugiere que no hay claridad en dichos recuerdos. En el campo del símil aparece un fenómeno particular, lo mismo que se podría argumentar sobre la similitud entre metáfora y símbolo. El símil compara objetos con una metáfora y una personificación como el utilizado en el verso noveno y decimosegundo. La figura de la personificación se encuentra en más versos (en el cuarto, decimotercero y decimocuarto). En ellos se construye a manera de cuerpo, el otro o el amado, a partir de su sonrisa.

El campo de la antítesis ubica sus figuras en el tercer y noveno verso en las motivos que sugieren que el frío se enciende como fuego y la lámpara, objeto que emite luz, que se contrapone a un "hueco", sustantivo que denomina a un lugar que no deja escapar la luz o no está iluminado. Ambas forman parte del campo figurativo de la antítesis. 
Se puede afirmar que las figuras recrean un escenario narrativo antitético y nostálgico brevemente iluminado por la sonrisa del amado en los recuerdos. Los campos repercuten en la configuración del pensamiento de la añoranza del amado, pero al mismo tiempo recrea un ambiente reflexivo donde la realidad se mezcla entre los recuerdos. Antes de analizar esta dicotomía presentaremos al interlocutor.

\subsection{INTERLOCUTOR}

El análisis de las figuras permite concretizar al interlocutor al que se dirige el hablante: la persona amada. El interlocutor aparece en forma intangible en el recuerdo. Aquel es quien mueve la temática del poema puesto que es el motivo que brinda el matiz nostálgico al poema. Un recurso que se complementa con el efecto dramático es el intento de personificación a partir de su sonrisa. La sonrisa emerge del silencio y musita el deseo de vivir, de soñar y viajar. Este pequeño discurso optimista es tan efímero que se apaga con la ausencia, nombrada en el octavo verso.

En los siguientes versos el interlocutor se vuelve brevemente más tangible. Por ejemplo, en el decimoprimer verso se incluye la persona gramatical en plural "nosotros", pero se evita la descripción por lo que la persona continua siendo tácita. Esta inclusión condensa su corporalidad acercándolo al yo, pero desvaneciéndolo fuera de los recuerdos mencionados en el verso anterior. Por este motivo creemos que el amado es representado en forma de silueta que se desvanece, puesto que ambos (amado y amante) se autoobservan en el espejo y solo ven el vacío de mortandad. Este personaje se puede clasificar como un locutor personaje, que solo aparece en las contemplaciones y meditaciones de la voz poética. Goza de características propias de un recuerdo, por eso es un ente incorpóreo. Su representación da un matiz romántico al poema y a su vez sirve como objeto de una breve evasión en los recuerdos del hablante. Pero al mismo tiempo ofrece una reflexión sobre la ausencia del individuo, ausencia que acompañará a la voz poética a la realidad una vez se aproxime a ella. Visualizamos un constructo simbólico a partir de los recuerdos y lo incorpóreo mediante las palabras. Para profundizar en este aspecto analizaremos el siguiente nivel. 


\subsection{TÉCNICAS ARGUMENTATIVAS}

Este poema utiliza un tipo de argumento llamado por Perelman y Olbrechts-Tyteca como la pareja "apariencia-realidad" que pertenece a los argumentos de la disociación de las nociones. Este tipo de razón se define como aquel que pretende confundir al interlocutor sobre la diferenciación entre realidad y apariencia. El mundo aparente deja claro la posibilidad de su contradicción mientras que lo real aparece como forma concreta:

El palo, hundido parcialmente en el agua, parece que está doblado, cuando lo miramos y recto cuanto lo tocamos; pero, en realidad no puede estar doblado recto al mismo tiempo. Mientras que las apariencias pueden oponerse, lo real es coherente; el efecto de su elaboración será el de disociar, entre las apariencias, las que son engañosas de las que corresponden a lo real $(1989$, p. 633).

Para esquematizar su análisis los autores llaman apariencia al término I y realidad al término II. $\mathrm{Si}$ aplicamos este análisis al poema "XV" de inmediato aparece la diferenciación entre la apariencia del recuerdo y la realidad del mundo tangible. El hablante intenta confundir argumentando en el segundo verso: el viento y el agua son una fantasía absurda. No obstante, la verdadera apariencia se sitúa en el recuerdo con las manifestaciones metonímicas del amado y la contemplación de ellos a una imagen contenida en el reflejo de un espejo. El sentimiento de vacío es el que termina la ensoñación y enfrenta al amante con la realidad, término II, que queda como niebla y donde los recuerdos se pierden.

El siguiente argumento se denomina enlace con lo simbólico, el cual se sustenta con la permisión del hablante al lector para visualizar su mundo interior creado con palabras. Allí cobran sentido sus pensamientos figurativos. Los autores Perelman y Olbrechts-Tyteca definen a la razón propuesta como una interacción que encierra una carga sostenida por el símbolo. Dicha relación crea una especie de capa mítica o especulativa que no rompe con la carga representativa de su representación:

El símbolo, a nuestro juicio se distingue del signo porque no es puramente convencional; si posee una significación y un valor representativo... para que desempeñe su papel, es 
preciso que el símbolo y lo simbolizado se integren en una realidad mítica o especulativa, en la que participan recíprocamente (1989, pp. 508-509).

El símbolo posee una significación, pero también posee una barrera de hermeticidad. Como ya anticipamos el hablante modula esta barrera para permitirnos acceder y captar la fuerza comunicativa de su mensaje. Dicho enlace entre los símbolos representados en el poema se realiza a partir del espejo que rompe con la ensoñación y refleja lo que sucede en verdad: "Los dos contemplamos el paisaje / como una imagen muerta" (Westphalen, 2018, p. 60) Lo que simboliza la palabra es la capacidad de comunicar. La voz lírica deja en claro esto cuando en el verso decimocuarto menciona su liberación desde su mundo interior al mundo concreto a partir del desengaño de entender la ausencia del amado. La capacidad de comunicar de la palabra rompe sus murmullos sugeridos en rumores musitados por el interlocutor: el deseo de viajar, de soñar y vivir. Luego de salir del silencio su mensaje se hace plausible. La realidad es diferente a la ensoñación y es algo que "parece" aceptarse. Finalmente, para profundizar en el "parecer" analizaremos la visión del mundo a partir de la reflexión entre realidad y ensoñación.

\subsection{VISIÓN DEL MUNDO}

Hasta el momento hemos mencionado los deseos y motivos que mueven al hablante a idear esta expresión simbólica a través de las palabras. Intentaremos profundizar un nivel más en este aspecto para internarnos en la visión del mundo. Para ello, nos basaremos en la conceptualización de estilos de pensamiento desarrollados por Giovanni Bottiroli. Este autor es tomado como marco teórico por Camilo Fernández en su análisis sobre el ensayo de Vargas Llosa La civilización del espectáculo. Los estilos mencionados son divididos en tres:

En primer lugar, el separativo que es rígido y tiende a jerarquizar conscientemente las categorías eliminando las ambigüedades [...] En segundo término, el distintivo que implica el funcionamiento de una inteligencia estratégica que implica el tratamiento de las oposiciones y la flexibilidad del pensamiento [...] Finalmente, el confusivo (neologismo que no posee ninguna connotación peyorativa) [...] tiende a lo cíclico frente a la linealidad del régimen separativo (2017, p. 188). 
Categóricamente los estilos mencionados son tres. Sobre este poema propondremos una visión del mundo cíclica equiparándolo al estilo confusivo. La primera razón recae en que el hablante oscila entre estas dos realidades representadas: la más intimista, dentro de su psique, donde surgen las emociones y la sensibilidad propiciadas por el amado; la otra es la realidad. La segunda razón se sustenta porque la recreación de la realidad se hace nebulosa, en aquel lugar casi es posible perder el hilo diferenciador entre la psique y lo real. No obstante, podemos palpar terreno tangible cuando de un tirón nos extrae mediante la mención del "ahora", en el penúltimo verso. A pesar de que la realidad continúe nebulosa, somos conscientes de que la interiorización ha culminado y acerbamente compartimos el deseo por la persona amada. Por estas razones establecemos una visión confusiva del mundo donde seguimos al amante a través del discurso simbólico que plantea un viaje entre dos realidades: la interna y la externa.

\section{EL SIMBOLISMO DE JULIA FERRER EN "POEMA": ANÁLISIS COMPARATIVO}

Realizar una comparación en el sentido que propone Albaladejo requiere equiparar características, aspectos, concepciones y estructuras de un objeto a otro. Además, dicha interacción promueve la creación de un nuevo conocimiento basado en la interacción de diferencias y semejanzas. En palabras del autor esta comparación se realiza a través de dos poéticas:

La poética tiene un componente de comparación, como lo tienen todo conocimiento y toda disciplina. Conocemos, en parte, comparando el objeto de conocimiento, sus características, sus aspectos, su configuración, con otros objetos que conocemos o cuyo conocimiento estamos adquiriendo [...] Así, el estudio de la Literatura incluye la comparación entre autores, entre obras, entre períodos históricos... y esta comparación se hace unas veces de manera implícita e intuitiva y otras de manera explícita y sistemática (2008, p. 251).

Se deduce que Albaladejo otorga suma importancia al momento de adquirir conocimientos, tanto es así que inclusive propone que la comparación sucede 
inconscientemente. Esta comparación tendrá una estructura similar al análisis anterior. Sin más iniciaremos, en primer lugar con una comparación entre los títulos.

Interpretamos que este poema además de utilizar el símbolo posee dos puntos de comparación con el poema "XV". El primero sucede porque utiliza el titulo sugerente: "Poema". Una expresión que lo equipara al matiz de la palabra fugaz utilizado por Westphalen, porque es un sustantivo estándar que podría titular cualquier texto con la forma de un texto poético. El segundo punto es que la temática que sostiene el poema es amorosa, otra forma de contacto con el poema " $\mathrm{XV}$ ".

Sin embargo, la representación del amor difiere en que en el poema de Julia Ferrer pretende exteriorizar y otorga un mayor peso a la sensación que a la psique, puesto que el hablante realiza una interacción más visceral con el amante. Esta es más efusiva, debido a elementos como el sufrimiento, el miedo y la sangre, en los versos: noveno, decimotercero y vigésimo, respectivamente. Esta observación es la que sustenta la tesis del poema: la expresión del sentimiento a través del símbolo.

\subsection{SEGMENTACIÓN}

Con motivo de organizar estos elementos iniciaremos la segmentación estructural. Este poema exceptúa la narración y presenta una estructura de tres partes. La primera estrofa, del primer al cuarto verso, se adecua al exordio. Los versos del quinto al vigesimoprimero corresponden a la argumentación del poema en la que el hablante realiza una metáfora comparativa entre su amado y el ángel expulsado del paraíso. En este caso la voz menciona que se escapó y no fue expulsado, por lo que se puede entender la connotación negativa que carga el amado, un ser no adecuado a las reglas, alguien que pretende marginarse. La estrofa final equivale a la peroración donde se reafirma la tesis y se recalca la debilidad que se siente por la persona amada. 


\subsection{CAMPO FIGURATIVO}

El uso de la simbolización en este poema, comparado al de Westphalen, tiene una aparición más abundante y referencian al tema bíblico además del natural. Las figuras sugieren una poética más esteticista que pretende aglutinar el contenido. El poema utiliza el campo figurativo de la metáfora y el símbolo. Su mundo no se interioriza en una realidad mental, sino concreta. Esto se muestra cuando el hablante focaliza su atención en el amado y utiliza la figura de la metonimia para construir un espacio similar a una habitación donde se encuentran ambos: "y se ocultó detrás de la cortina" (Ferrer, 1981, p. 4).

Sus sugerencias son llevadas un más allá de una referencia, por lo que su sugerencia se hace más gaseosa: "mi corazón /sufre / y pisa almendras" (Ferrer, 1981, p. 4). El sustantivo de la almendra funge como símbolo que expresa una significación apenas comprensible, aunque se podría catalogar como positiva. Otros símbolos expresan su relación con la música, como el "teclado", y otros con la pasión, como la "sangre"; ambos aparecen en el verso vigésimo y en el vigesimoprimero, respectivamente. El poema utiliza metáforas clásicas, como la que aparece en el sexto verso, donde "bocanadas" se reemplaza por rapidez o el "hombre fugitivo" se relaciona al ángel escapado del cielo y a quien el hablante muestra debilidad. Las metáforas, de igual manera, tal como muestra la interpretación, pretenden adensar la comunicación. Nuestra interpretación propone que la voz poética se sirve de los símbolos como material estético y los utiliza para realizar la expresión sentimental, cuya idea sobre esto es irrepresentable.

\subsection{INTERLOCUTOR}

La interlocución que aparece en el poema "Poema" es similar al del poema "XV". La voz poética configura un interlocutor personaje cuya interacción con él se efectúa a través de una mirada y el silencio. La primera aparición del interlocutor sucede a partir de una metonimia que intercambia consecuencia por causa, o exhalación por cuerpo: "vaho de los hombres". (Ferrer, 1981, p. 4). El personaje aparece primero disperso porque el hablante utiliza el plural, luego se concentra en uno solo, este cumple la función de ser el hombre, 
metafóricamente comparado con el ángel desterrado del cielo: "el miedo / de aquel remoto esclavo / que se escapó del cielo”. (Ferrer, 1981, p. 4) Es interesante como la voz trata de abogar por el amado intentando representarlo como un esclavo que escapa de la opresión divina. No obstante, esto no escapa de su representación negativa, debido a que la metáfora que utiliza es la del ángel caído. Este personaje sirve como móvil del poema, puesto que el hablante deja en claro su debilidad por aquel. A continuación representa una escena donde ambos están en la misma habitación, a partir del verso decimonoveno. La particularidad de este personaje es que no pretende comunicar, aunque sí se presenta para que el amante exprese sus emociones y desarrolle su discurso simbólico, que es todo el poema en sí.

\subsection{TÉCNICAS ARGUMENTATIVAS}

La estructuración del poema sigue un patrón similar a una argumentación aparentemente cohesionada. No obstante, el registro poético influye en la interpretación que damos a los propios conectores: “y yo [...] y es / que la vida [...]”. (Ferrer, 1981, p. 4) La unida a través de conectores de nexo causal "y" en ocasiones se puede interpretar como porque. Este tipo de argumentación según Perelman y Olbrechts-Tyteca (1989) está basada en la estructura de lo real e intenta aproximar "dos acontecimientos opuestos" (p. 405): el rechazo al amado y la aceptación de este. Interpretamos que ambos argumentos evidencian el efecto que produce la interacción con el amado. Las partes de la argumentación, premisas y conclusión, están unidas a través de los nexos causales, pero el halo simbólico afecta la conexión de estos. La figura anafórica de la "y" desarticula su sentido desde el inicio del verso, debido a su repetición constante. Así, resulta complicado establecer una argumentación, principalmente porque se hace distorsión de la significación de los conectores.

\subsection{VISIÓN DEL MUNDO}

Ahora a partir de nuestra reflexión sobre los aspectos tratados anteriormente compararemos la visión del mundo para profundizar hasta el nivel de la inventio. Proponemos un estilo 
separativo y distintivo para el poema, una posibilidad diferente frente al poema "XV”, el cual utilizaba un estilo más reflexivo y confusivo.

El estilo de pensamiento distintivo se decanta por la flexibilidad de pensamiento. Esto, porque precisamente antes del tercer verso aparece una actitud del hablante decidida: “y yo / que todo lo hago realidad". (Ferrer, 1981, p. 4) antes de enredarse con la silueta masculina que representa mediante la personificación de su vaho. La segunda razón recae en la manera de relacionarse con su interlocutor. Ella expresa "sufrimiento", "miedo", “confusión” pero no puede negar la inserción del amado en su vida, porque a partir de la sugerencia visceral a partir del sustantivo de la sangre, idea una concepción conflictiva sobre el amor, un amor que la aleja del mundo exterior (no realidad sino el mundo exterior a una habitación). Sin embargo, la repulsión que le causa su enamoramiento no es suficiente para que ella se aleje del amado. Su discurso recrea un vaivén entre el amor y el odio.

El final del poema es el siguiente: "el fugitivo aquél / mal fugitivo / osó mirarme cara a cara / iy todavía tenemos para rato!” (Ferrer, 1981, p. 4). Antes de iniciar algún discurso la narración se corta, ambos se miran, pero el verso final deja un final abierto no somos capaces de saber si continuarán mirándose o finalmente hablarán. Hasta ese momento el hablante comunicó parte de sus sensaciones a partir de sus recursos retóricos. No podemos dar cuenta de lo que sucede entre ambos ni podemos asignar un rumbo al curso que tomará el poema, solo sentencia que después de la mirada ambos continuarán realizando un acto oculto por el teclado, la cortina y la sangre, en ese sentido el poema hermetiza su propia lectura.

\section{CONCLUSIÓN}

Las dos poéticas utilizan recursos similares, pero sus tratamientos son diferentes. En el poema " $\mathrm{XV}$ " el hablante modula su registro de comunicación y crea una representación simbólica a través del lenguaje. El conflicto amoroso propicia una argumentación que muestra una realidad confusiva, cuyo escape es frustrado. La representación simbólica de 
esta aparece de forma fragmentada a través de los ojos de la voz poética. Los campos figurativos utilizados en el ideario sobre aquella crean un lazo con lo estético. Respecto al poema "Poema" afirmamos que el discurso se origina a partir de un amado. La voz lírica pretende utilizar el símbolo para intentar materializar, a través de una argumentación basada en la estructura de lo real, el conflicto amoroso. Su visión del mundo evita plasmar una representación de su contexto y representa una realidad idealizada, de matices bíblicos $\mathrm{y}$ viscerales referidos al sentimiento del amor.

\section{ANEXO}

\section{POEMA}

y yo

que todo lo hago realidad

me enredo mucho

con el vaho de los hombres

$\mathrm{y}$ es

que la vida a bocanadas va

pero en el fondo

mi corazón

sufre

y pisa almendras

y no sólo eso

sino también

el miedo

de aquel remoto esclavo

que se escapó del cielo

tomó la vida

como quien va a su casa

me dejó esta piel suave

y se ocultó detrás de la cortina

mientras su sangre goteaba en

el teclado 
el fugitivo aquél

mal fugitivo

osó mirarme cara a cara

¡y todavía tenemos para rato!

(Ferrer, 1981, p. 4).

\section{REFERENCIAS BIBLIOGRÁFICAS}

ALBALADEJO, T. (2008). Poética, Literatura comparada y análisis interdiscursivo. Acta Poética, 29(2), 245-275.

ARDUINI, S. (2000). Prolegómenos a una teoría general de las figuras. Murcia: Universidad de Murcia.

CISNEROS, A. (1992). El Surrealismo vergonzante (tres poetas peruanos). Recuperado de https://books.openedition.org/ifea/2219?lang=es [Consulta: 15 de junio de 2020]

DE LA VEGA, P. (2007). Reencuentro con Yolanda Westphalen: Palabra fugitiva. Gaceta Cultural del Perú, 25, 36-37.

FERNÁNDEZ COZMAN, C. (2017). El estilo separativo, la inteligencia figural y el etnocentrismo en La civilización del espectáculo de Mario Vargas Llosa. Acta Literaria, 54, 187-195. Recuperado de http://www.scielo.cl/pdf/actalit/n54/07176848-actalit-54-00187.pdf [Consulta: 15 de junio de 2020]

FERRER, J. (1981). Poema. La casa de cartón, 3(2), 4.

PERELMAN, CH. \& OLBRECHTS-TYTECA, L. (1989). Tratado de la argumentación: La nueva retórica. Madrid: Gredos.

RANCIÈRE, J. (2015). Mallarmé: La política de la sirena. (trad. Durán, C., González, V. y Matamala, C.). Buenos Aires: LOM.

SUMALAVIA, R. (2003). Nuevas narrativas peruanas: la Generación del 50 ahora. Recuperado de https://www.desco.org.pe/recursos/sites/indice/64/293.pdf [Consulta: 15 de agosto de 2020].

TROIANO, M. (2008). "Viviendo el tiempo" de Yolanda Westphalen: una elegía para perdura. Recuperado de http://scriptura-blog.blogspot.com/2008/12/viviendo-eltiempo-de-yolanda.html [Consulta: 15 de agosto de 2020]. 
UNIVERSIDAD NACIONAL MAYOR DE SAN MARCOS (2018). Fondo Editorial publica libros sobre la revista "Variedades" y la poesía de Yolanda Westphalen. Recuperado de http://www.unmsm.edu.pe/noticias/ver/fondo-editorial-publica-librossobre-la-revista-variedades-y-la-poesia-de-yolanda-westphalen [Consulta: 15 de agosto de 2020].

WESTPHALEN, Y. (2018). Obra completa. Poesía. Lima: Universidad Nacional Mayor de San Marcos. 